\title{
El principio de la prohibitio reformatio in pejus en el derecho procesal penal del Ecuador. Una mirada histórica y una mirada actual \\ The Principle of the Prohibitio Reformatio in Pejus in the Criminal Procedural Law in Ecuador. An Historical and Present View
}

Robert Guevara Elizalde*

* Doctor en Jurisprudencia por la Universidad de Guayaquil. Magíster en Derecho Constitucional por la Universidad Católica, Santiago de Guayaquil. Profesor de Derecho Constitucional, Derecho Procesal. Constitucional y Derecho Procesal Penal de la Universidad de Guayaquil, Facultad de Jurisprudencia. Código postal: EC090303. Dirección: Hurtado 205 y Machala, segundo piso, oficina $N^{\circ}$ 2. Guayaquil, Ecuador. Correo electrónico: robertguevaraeli@hotmail.com

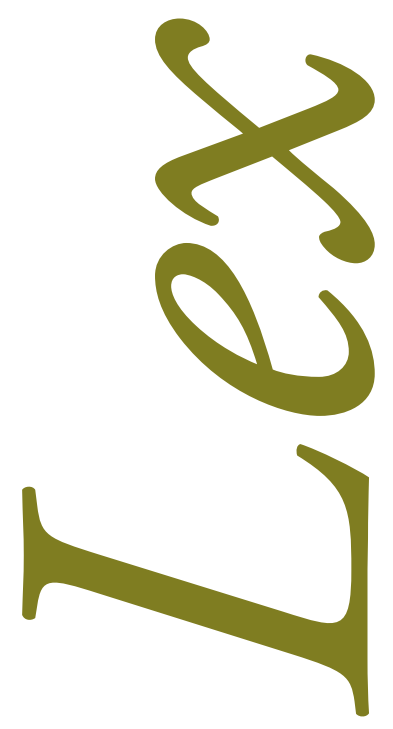




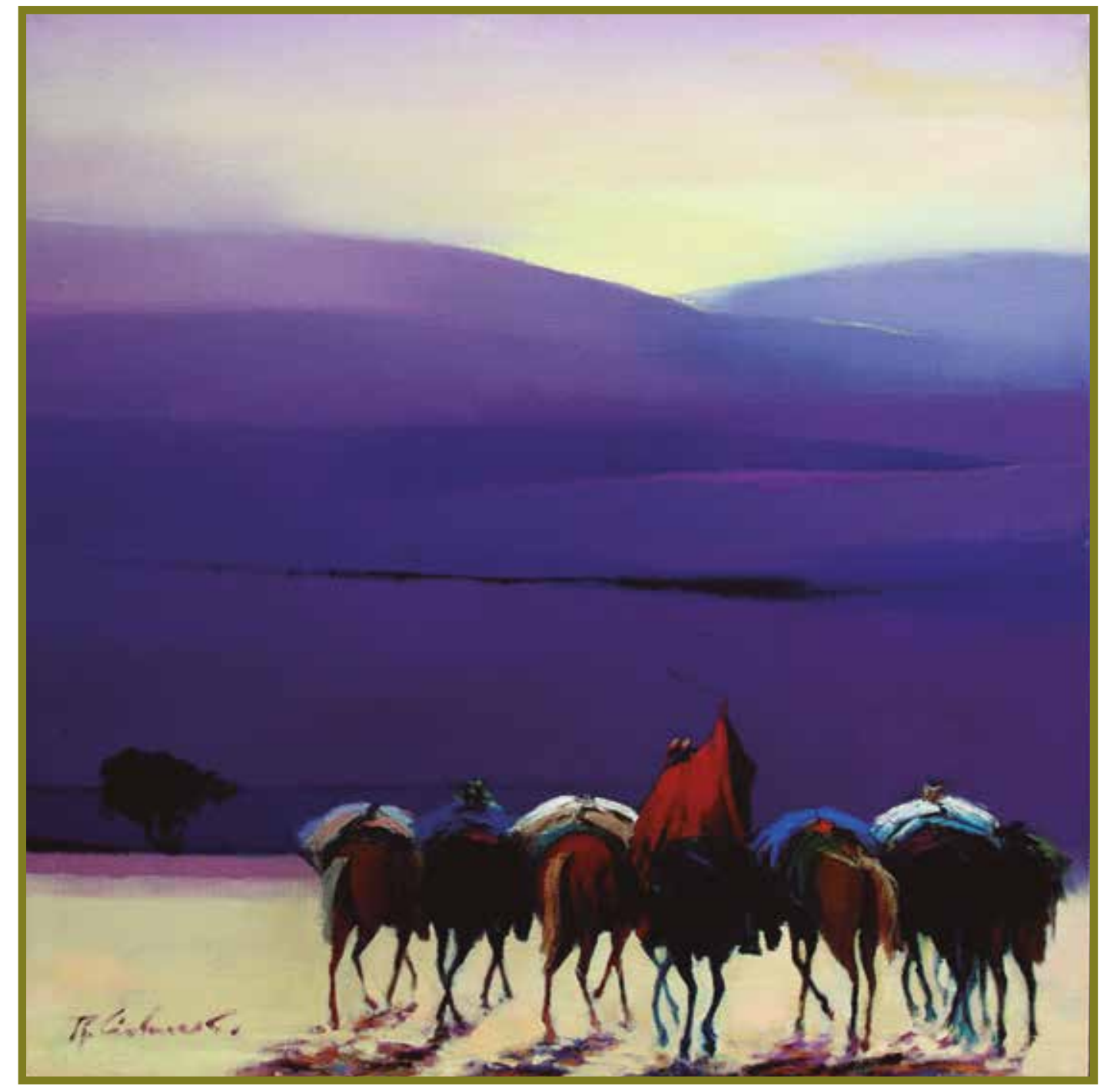

Raúl Cárdenas. Arrieros al amanecer. 60 x $50 \mathrm{~cm}$. 


\section{RESUMEN}

A esta institución procesal penal, materia de este ensayo, se la estudia como una garantía para el procesado dentro de un juicio en el que ha sido condenado. En esta garantía, el juez superior no puede agravar la pena impuesta y recurrida por el condenado. Este estudio examina su aparición histórica, su ejercicio pleno y los casos por los que se concreta su abolición en el Ecuador. Esta evolución se describe en este breve estudio.

Palabras clave: procedimiento penal, principio, proceso, garantía, juicio, sentencia condenatoria, recursos, agravación, apelación, acusados, condenados, jurisprudencia, aplicación, abolición.

\section{ABSTRACT}

The Criminal Procedural Institution analyzed on this essay, is studied as a guarantee for the defendant in a trial after which he received a conviction. It guarantees that the Superior Court cannot aggravate the conviction imposed and appealed by the defendant. This paper examines its historical appearance, its full exercise and the cases by which its abolition is set in Ecuador.

Key words: criminal procedure, principle, process, guarantee, judgment, conviction, action, aggravation, appeal, defendant, convicted, jurisprudence, application, abolition. 


\section{INTRODUCCIÓN: EL CONCEPTO}

Debemos entender en sentido coloquial y en el uso jurídico procesal que este principio se refiere a la probibición dirigida al juez superior de reformar una sentencia en perjuicio del recurrente, limitando la posibilidad judicial de que se haga más gravosa la situación de quien impugna en orden a evitar la desmotivación o disuasión de la interposición de un recurso respecto de una sentencia, que le corresponde conocer al juez ad quem, por algún remedio o recurso interpuesto. Este principio ha sido tratado por la doctrina y la jurisprudencia latinoamericana, como puede verse, al menos, en México ${ }^{1}$, Argentina $^{2}$, Colombia ${ }^{3}$, Perú ${ }^{4}$ y Ecuador.

1 Marco Antonio Díaz de León, Diccionario de derecho procesal y de términos usuales en el proceso penal (México D. F.: Porrúa, 1986), 2040.

2 Jorge Vázquez Rossi, Derecho procesal penal, tomo II (Buenos Aires: Rubinzal Culzoni, 2004), 477; Ricardo Levene, Manual de derecho procesal penal, tomo II (Buenos Aires: Depalma, 1997), 655 y 656; Jorge E. Claria Olmedo, Derecho procesal penal, con la colaboración de José Cafferata Nores, Cristina José de Cafferata y Jorge Montero, tomo II (Córdova: Marcos Lerner, 1984), 368; Lucio R. Gernaert Willmar, Manual de los recursos, prólogo de J. E. Claria Olmedo (Buenos Aires: Abeledo Perrot, 1985), 55 y ss.; Eduardo M. Jauchen, Derechos del imputado, primera edición (Buenos Aires: Rubinzal Culzoni, 2007), 455 y ss.; Julio Bernardo José Maier, Derecho procesal penal (Parte general, actos procesales), tomo III, primera edición (Buenos Aires: Editorial del Puerto, 2011), 313 y ss.

3 Jaime Bernal Cuéllar y Eduardo Montealegre Lynnet, El proceso penal, tercera edición (Bogotá: Universidad Externado de Colombia, 1995), 244. Ver también Fernando Quiceno Álvarez, ed., Jurisprudencia penal. Repertorio jurisprudencial seleccionado. Primer semestre 2002, primera edición (Bogotá: Editora Jurídica de Colombia Ltda., 2002); Héctor Jaime Laverde Noboa y Juan Carlos Arias Duque, "Audiencias de sustentación oral de recursos”, en El proceso penal acusatorio en Colombia. Las audiencias en el juicio oral, primera reimpresión de la primera edición, tomo II (Bogotá: Ediciones Jurídicas Andrés Morales, Bogotá, 2007), 327 y 328; Fabio Espitia Garzón, Instituciones de derecho procesal penal, séptima edición (Bogotá: Legis, 2010), 259 y 265.

4 Alonso Raúl Peña Cabrera Freyre, Manual de derecho procesal penal (teoría, práctica y jurisprudencia), con la colaboración de Raúl Gonzalo Peña Freyre, segunda edición (Lima: Rodhas, 2008), 596 y ss. También puede verse Pablo Sánchez Velarde, El nuevo proceso penal, primera edición (Lima: Idemsa, 2009), 410 y 411; José Antonio Neyra Flores, Manual del nuevo proceso penal y de litigación oral (Lima: Idemsa, 2010), 373, 374, y 379; César San Martín Castro, Derecho procesal penal, segunda edición actualizada y aumentada, tomo II (Lima: Grijley, 2003), 941 a 953. Tal vez este último autor sean el que más extensamente ha fundamentado este principio en el Perú. 


\section{ORIGEN ROMANO}

La doctrina del principio de la probibitio de la reformatio in pejus, y su aplicabilidad en todas las impugnaciones devolutivas, aparentemente se origina de un célebre pasaje de Ulpiano (49, I.I: Licet enim non unquam bene latas senttentias un pejus reformet: pues es lícito en ocasiones reformar empeorando las sentencias bien pronunciadas), que puede enunciarse así de manera general: "Prohibición de pronunciar una nueva sentencia más desfavorable al imputado sobre el mismo objeto".

\section{BREVE HISTORIA EN EL ECUADOR}

En una de las más antiguas obras de procedimiento ecuatoriano, como la de Pedro Fermín Cevallos, ${ }^{5}$ publicada en 1867, a pesar del gran conocimiento del autor sobre el procedimiento penal, civil y mercantil de su época, no se informa aún, en su libro, respecto de la prohibición de reformar en perjuicio del reo o del recurrente.

El principio de la prohibitio reformatio in pejus, tal vez, por primera vez, fue solo mencionado en el Ecuador en 1951 al referirse respecto del recurso de apelación, en nuestra literatura procesal penal por Antonio Borrero $\mathrm{Vega}^{6}$, sin desarrollarlo mayormente.

Después este principio fue brevemente explicado por Víctor Llore Mosquera ${ }^{7}$ en la doctrina procesal penal ecuatoriana.

Actualmente la doctrina contemporánea más seria ${ }^{8}$ lo acepta mayoritariamente en el país.

5 Pedro Fermín Cevallos, Instituciones de derecho práctico ecuatoriano, presentación del Dr. Fausto Sánchez H., reimpresión de mayo de 1994 (Quito: Consejo General de Instrucción Pública, 1867).

6 La referencia más antigua, sobre el principio, entre los libros sobre procedimiento penal en el Ecuador, la encontramos en la obra de Antonio Borrero Vega, Estudio del código de procedimiento penal (Cuenca: Talleres Gráficos de la Universidad de Cuenca, 1951), 256.

7 Víctor Llore Mosquera, Compendio de derecho procesal penal ecuatoriano, tercera edición (Cuenca: Fondo de Cultura Ecuatoriano, Offset Atlántida, 1979), 126 y 127, nos dice: "La revocación in pejus es totalmente contraria al espíritu de la apelación. Por esta se da competencia al juez ad quem para que decida si la pena impuesta en la sentencia es no justa, pero nunca para que agrave la situación del penado que, al recurrir de la sentencia condenatoria, lo hace porque estima que ella es injusta. Permitir la revocación en perjuicio de imputado cuando no ha mediado reclamo de las otras partes procesales significaría colocar al sindicado en posibilidad de abstenerse de impugnar una sentencia injusta o su juicio, por el fundado recelo de que se le agrave la pena. El Tribunal Supremo de justicia ha reconocido ya la vigencia de este principio doctrinario en los fallos publicados en los números 7 y 9 de la VIII Serie de la Gaceta Judicial correspondiente al año 1955”.

En cambio, en un trabajo anterior de este autor: "Programa analítico para la enseñanza del derecho procesal penal", Anales de la Universidad de Cuenca XII, n. ${ }^{\circ}$ 3-4 (julio-diciembre de 1956), no se hace referencia a este principio comentado aquí.

8 Guillermo González García, Manual de procedimiento penal (Quito: Editorial Universitaria, 1967), 287 y 288 ; Jorge Zavala Baquerizo, El proceso penal ecuatoriano, tomo V, segunda edición (Guayaquil: Imprenta A. G. Senefelder, 1975) 114 y 115; Alfonso Zambrano Pasquel, "La abolición de la reformatio in pejus", La Ley, n. ${ }^{\circ} 6$ (julio de 1977), y reimpreso como "La abolición de la prohibición de la reformatio in pejus" en Opúsculos penales (Guayaquil: Ediciones Jurídicas La Ley, 1977), 9 y ss.; Walter Guerrero Vivanco, El proceso penal, tomo IV, cuarta edición (Quito: Pudeleco Editores S. A., 2004), 232; Ricardo Vaca Andrade, Manual de derecho procesal penal, volumen 1 (Quito: Corporación de Estudios y Publicaciones, 2001), 409; Efraín Torres Chávez, Breves comentarios al Código de Procedimiento Penal (con práctica 


\section{LOS PROYECTOS DE CÓDIGO DE PROCEDIMIENTO PENAL ECUATORIANOS Y LA REFORMATIO IN PEJUS}

- El proyecto de 1948 del Código de Procedimiento Penal del Dr. Reinaldo Cabezas Borja9 no incorpora a su texto la prohibición de reformar en perjuicio.

- En algún proyecto de ley de la universidad de Cuenca, ${ }^{10}$ de 1963 , respecto del Código de Procedimiento Penal, expuso el principio de la prohibición de reformar en perjuicio, con claridad. ${ }^{11}$

- Se ha dicho que la codificación del CPP de 1970 fue redactada sobre la base del proyecto elaborado por Víctor Lloré Mosquera.

- El proyecto de Código de Procedimiento Penal del profesor Jorge Hugo Rengel ${ }^{12}$ en 1982, incorpora expresamente al CPP la figura de la adhesión al recurso (Art. 417), que es una de las formas de eliminar este principio de la prohibición de la reforma en perjuicio; es más, dicho proyecto de manera expresa es abiertamente contrario al principio aquí estudiado. ${ }^{13}$

- El Ante proyecto Zavala del CPP de 1983.

- Ulteriormente, el mismo Dr. Zavala Baquerizo presentó un proyecto de reformas al CPP en el año 1987, remitido por el presidente de la Comisión de lo Civil y Penal Dr. Carlos Feraud Blum al presiente del Congreso Lcdo. Andrés Vallejo Arcos. Mediante oficio $\mathrm{N}^{\circ}$ 082-CLCP-P, Quito, abril 29 de 1987, que dejó intocado el principio estudiado.

penal), volumen 2 (Quito: Corporación de Estudios y Publicaciones, 2001), 150-151; Jorge Zavala Baquerizo, Tratado de derecho procesal penal, tomo IX (Guayaquil: Edino, 2007), 299 y ss.; Luis Cueva Carrión, El debido proceso, segunda edición (Quito: Ediciones Cueva Carrión, 2006), 139 y ss.; Luis Humberto Abarca Galeas, La defensa penal oral, tomo IX, primera edición (Quito: Editorial Jurídica del Ecuador, 2008), 106; Robert Guevara Elizalde, "La prohibición de reformatio in pejus en el Ecuador", inédito (Guayaquil, 2013).

9 Reynaldo Cabezas Borja, Proyectos de Código Penal y de Procedimientos Penales para la república del Ecuador (Quito: Talleres Gráficos Nacionales, 1948).

10 Instituto de Ciencias Penales de la Facultad de Jurisprudencia de la Universidad de Cuenca, Anteproyecto de Código de Procedimiento Penal del Ecuador (Cuenca: Talleres Gráficos de la Universidad de Cuenca, 1963).

11 Ibidem. Art. 338.- "De mediar las mismas circunstancias con respecto al delito y a la situación personal de los sindicados cuando estos sean varios, la decisión del juez superior tendrá efecto extensivo con respecto al sindicado o a los sindicados que no hayan ejercido el derecho de impugnar los actos del juez. Pero no tendrá tal efecto si en ella se agravare de manera alguna la situación en que se encuentre el imputado que no impugnó...”. Ibidem. Art. 342. "De no mediar recurso del representante del Ministerio Público, el tribunal superior no podrá revocar o reformar la sentencia del inferior, impugnada por el sindicado, en perjuicio de este, agravando la pena que le hubiere sido impuesta."

12 Jorge Hugo Rengel, "Proyecto de Código de Procedimiento Penal", en Memorias de las VIII Jornadas Iberoamericanas de Derecho Procesal, tomo II, ed. por la Corte Suprema de Justicia (Quito: Editorial Ecuador, 1983),167-290.

13 Jorge Hugo Rengel, "Proyecto de Código de Procedimiento Penal”, 260. Como se puede ver en el Art. 416.- "Apelación de la sentencia. La Corte Suprema o la Corte Superior según los casos, analizarán íntegramente la sentencia de primer grado y dictarán con amplia libertad su decisión, así favorezca o perjudique a quien haya interpuesto el recurso, teniendo en cuenta el interés público del Estado en la acción penal.” 
- En 1992, el Proyecto de Código de Procedimiento Penal, de la Corte Suprema de Justicia, que fuera presentado por su presidente: Dr. Walter Guerrero Vivanco.

- El anteproyecto de CPP elaborado por profesores de la Universidad de Guayaquil, Drs. Jorge Zavala Baquerizo, Maximiliano Blum Manzo y abogado Byron López Castillo, del 1 de noviembre del 2007. En su Art. 295 contiene este principio.

\section{LA DOCTRINA DE LA PROHIBITIO REFORMATIO IN PEJUS EN EL ECUADOR}

Este principio no fue recogido expresamente por el legislador en los códigos de procedimiento penal ecuatorianos hasta antes del CPP de 1983, cuando es recogido y llevado a convertir en ley, por primera vez, como lo pone de manifiesto en una exposición de motivos, ${ }^{14}$ sobre las reformas al CPP ${ }^{15}$ en donde explica el Proyecto Zavala de CPP de 1983, del Dr. Jorge Zavala Baquerizo, ${ }^{16}$ que es el profesor ecuatoriano que más ampliamente ${ }^{17}$ ha tratado, hasta ahora, este y otros temas procesales penales en el Ecuador.

Poco después, inspirándose en gran parte en el estudio de Zavala Baquerizo de su segunda edición del libro El proceso penal ecuatoriano ${ }^{18}$ de 1975 , aunque no lo sigue en todas sus conclusiones, aparece, de Alfonso Zambrano Pasquel, un estudio específico y original, pues, se fundamentaba en los estudios de la jurisprudencia ecuatoriana, cosa que muy pocos autores hacían y hacen. Y por ello muy llamativo de atención, por entonces, de manera particular y

14 El CPP de 1983, Art. 347, decía: "Ningún Tribunal Superior podrá empeorar la situación jurídica del procesado, si este ha sido el único recurrente".

15 Jorge Zavala Baquerizo, Comentarios al Código de Procedimiento Penal, en Memorias del seminario de 30 de agosto al 2 de septiembre de 1983 (Loja: Colegio de Abogados de Loja, 1985), 146. Aunque la orientación que aparece es que este principio es aplicable dentro del recurso de apelación

16 Jorge Zavala Baquerizo, Exposición de motivos sobre las reformas al Código de Procedimiento Penal (Guayaquil: Colegio de Abogados del Guayas, 1984), 324, señalaba que "En el Código anterior no se decía nada al respecto y por ello, algunas veces una de las salas de la Corte Suprema admitía el principio antes indicado, y en otras salas diferentes se negaba dicho principio. De ahí la necesidad de que de manera clara se estableciera legalmente que se prohibía la reforma en perjuicio del único recurrente...”. Mantiene en cambio, una orientación de la aplicación de este principio durante la etapa de impugnación en general.

La fundamentación de la incorporación de dicho instituto procesal al derecho positivo procesal penal ecuatoriano la explica Zavala Baquerizo en otro de sus libros que explican las razones que tuvo el autor, y en su trabajo "Comentarios al Código de Procedimiento Penal”, 146, donde dice que "...por lo general en nuestro medio era corriente que si el sindicado apelaba de una sentencia y era el único apelante, el tribunal del recurso resolvía aumentarle la pena a su leal saber y entender; es decir que el pobre sindicado y procesado sufría un doble agravio: el agravio que le impuso el juez inferior y el agravio de aumentarle la pena. Y eso era contrario a la finalidad del recurso. ¿Cuál es la finalidad del recurso? Que se modifique o que se revoque la providencia que causa agravio; pero si encima de eso, ni se reforma ni se revoca sino que se aumenta la pena rectificando la anterior, ya hay acción contraria al elemental principio del derecho de defensa. Por eso nuestro Código de Procedimiento Penal actualmente prohíbe la reforma en perjuicio del sentenciado cuando es el único que ha recurrido; no es lo mismo cuando recurre el acusador particular o recurre el fiscal; alli si hay derecho para que el Tribunal Superior pueda aumentar la pena; porque los argumentos de recurso de la parte activa del proceso le permiten tal resolución, pero mientras solamente el acusado sea el recurrente, no ha lugar a ello."

17 Zavala Baquerizo, Tratado de derecho procesal penal...

18 Zavala Baquerizo, El proceso penal ecuatoriano... 
especializada del uso de la jurisprudencia de la Corte Suprema de Justicia, sobre este principio escrito por el Dr. Alfonso Zambrano Pasquel en 1977. ${ }^{19}$

Posteriormente, en 1992 el Proyecto de Código de Procedimiento Penal, de la Corte Suprema de Justicia, que fuera presentado por su presidente, el Dr. Walter Guerrero Vivanco, encontramos mencionado este principio; empero, se lo ubica en Capítulo del Recurso de Casación, es decir, solo aplicado en esta forma de impugnación.

Finalmente, las reformas al CPP publicadas en el Suplemento del Registro Oficial No. 555 de 24 de marzo del 2009 modificaron este principio, relativizándolo, haciéndolo extensivo ahora a cualquier recurrente, aunque este no sea el sentenciado a condena.

\section{LA JURISPRUDENCIA ECUATORIANA CREADORA PRÁCTICA DE LA PROHIBICIÓN DE REFORMAR EN PERJUICIO}

Debe convenirse que en el Ecuador este principio es una elaboración indubitable de la jurisprudencia, como lo avizoró en 1977 Zambrano Pasquel, principio que ha sido aceptado en los autos y sentencias de la antigua Corte Suprema de Justicia, aunque antaño pocos fallos lo declararon inaplicable, lo cual motivó que para poner orden en la doctrina jurisprudencial de la época, se escribiera uno de los primeros estudios específicos sobre el principio de la prohibitio reformatio in pejus, como ya lo dije, por el eminente jurista peninsular Dr. Alfonso Zambrano Pasquel ${ }^{20}$ explicando su no "abolición" de la jurisprudencia ecuatoriana y algunas cuestiones conexas, allá por 1977. Mayores detalles in extenso pueden verse en el ensayo de Robert Guevara Elizalde. ${ }^{21}$

Debemos mencionar dos bloques de jurisprudencia a este respecto:

\section{VI.1. Sentencias que niegan la aplicación del principio reformatio in pejus}

En este resumen solo mencionaremos las sentencias que en la monografía están transcritas:

- Primera Sala de la Corte Suprema de Justicia, en la Gaceta Judicial, serie XII, No. 11, página 2277.

- Sentencia dictada por la Segunda Sala ${ }^{22},{ }^{23}$ de la Corte Suprema de Justicia, de fecha 17 de diciembre de 1980, por muerte de Jorge Flores en contra de Vicente Cantos.

19 Zambrano Pasquel, "La abolición de la reformatio in pejus", 23-29.

20 Zambrano Pasquel, "La abolición de la prohibición de la reformatio in pejus", 9 y ss.

21 Guevara Elizalde, "La prohibición de reformatio in pejus en el Ecuador".

22 José García Falconi, Setenta años de jurisprudencia de la Corte Suprema; José García Falconi, Código de Procedimiento Penal con jurisprudencia (Quito: 1984), 195; Galo Espinoza M., La más práctica enciclopedia jurídica: compendio de setenta años de jurisprudencia de la Corte Suprema de Justicia, tomo IV (Quito: Imprenta Don Bosco, 1999), 746-747.

23 Gaceta Judicial, serie XIII, No. 10, p. 2202, enero-abril 1981. Igualmente ver el fallo tomado de Galo Espinoza, La más práctica enciclopedia jurídica..., 746-747. 
- Sentencia dictada por la Tercera Sala ${ }^{24}$ de la Corte Suprema de Justicia, con fecha 26 de enero de 1982, juicio penal que por violación de una menor se sigue en contra de EOC, desechando el principio de la prohibitio reformatio in pejus.

- Resolución de Casación publicada en el Registro Oficial No. 153 de 22 de agosto del 2003. Corte Suprema, Primera Sala de lo Penal, caso No. 231-2003. ${ }^{25}$ Quito, 27 de junio del 2003. Las 10h 00.

\section{VI.2. Sentencias que aceptan la aplicación del principio reformatio in pejus}

- Gaceta Judicial, serie VIII No. 7, de 15 de julio de $1953^{26}$.

- Gaceta Judicial, serie VIII No. 9. ${ }^{27}$

- Gaceta Judicial, serie XII No. $11 .^{28}$

- Fallo dictado por la Quinta Sala de la Corte Suprema de Justicia publicada en la Gaceta Judicial, serie XII No. 12, página 2764.

- Gaceta Judicial, serie XVII, No. 2, página 469.

- Fallo de la Tercera Sala de la Corte Suprema, de fecha 7 de abril de 1976, juicio penal que por muerte de GBS se siguió en contra de IEES. ${ }^{29}$

- Sentencia dictada por la Quinta Sala ${ }^{30}$ de la Corte Suprema de Justicia, con fecha 18 de enero de 1982, por muerte de Andrea Zambrano Cevallos en contra de GHZC.

- Sentencia dictada por la Primera Sala ${ }^{31}$ de la Corte Suprema de Justicia, con fecha 21 de marzo de 1983, juicio penal por lesiones a Santos Medardo Vera, en contra de FVE.

- Sentencia de la Quinta Sala ${ }^{32}$ de la Corte Suprema de Justicia, fallo de fecha 27 de marzo de 1984, por delito de muerte de Juan Alberto Guarusha, que se sigue en contra

24 Espinoza M., La más práctica enciclopedia jurídica..., 462.

25 Gaceta Judicial, serie XVII, No. 12, p. 3858 a fs. 3859, mayo-agosto 2003.

26 Fallo tomado de Guillermo González García, Manual de procedimiento penal..., 287-288. Ulteriormente aparecerá citado por Jorge Zavala Baquerizo, El proceso penal ecuatoriano..., 114-115.

27 Fallo citado por Zambrano Pasquel, "La abolición de la prohibición de la reformatio in pejus", 13 y ss.

28 Fallo tomado de José García Falconi, 78 años de jurisprudencia penal ecuatoriana, primera edición (Quito: Producciones Gráficas, 1981), 122. Ver también: José García Falconi, Código de Procedimiento Penal con jurisprudencia..., 195.

29 Galo Espinoza M., Diccionario de jurisprudencia de la Corte Suprema de Justicia, tomo VI (Quito: Imprenta del Colegio Don Bosco, 1984).

30 Galo Espinoza M., Diccionario de jurisprudencia de la Corte Suprema de Justicia, tomo IV, segunda serie (Quito: Imprenta del Colegio Don Bosco, 1984), 461.

31 Espinoza M., Diccionario de jurisprudencia..., tomo VI, segunda serie, 574. Otra referencia: Primera sala, sentencia de fecha 17 de septiembre de 1985, juicio penal por muerte de Carlos Fco. Ávila, se siguió contra CMP.

32 Espinoza M., Diccionario de jurisprudencia..., tomo VI, segunda serie, 575. 
de JM. Sentencia recurrida únicamente por el representante del Ministerio Público: dictamen del Ministro Fiscal General, favorable al encausado.

- Sentencia dictada por la Primera Sala ${ }^{33}$ de la Corte Suprema de Justicia, dictada el 26 de julio de 1985, seguido en contra de VFVM por falsificación de documentos.

- Sentencia dictada por la Cuarta Sala ${ }^{34}$ de la Corte Suprema, fallo de fecha 31 de mayo de 1977.

- Fallo dictado por la Segunda Sala de la Corte Suprema de Justicia dictada el 2 de abril de $1976 .{ }^{35}$

- Fallo dictado por la Tercera Sala de la Corte Suprema de Justicia el 7 de abril de $1976 .{ }^{36}$

- Sentencia penal impugnada únicamente por el encausado: prohibición de empeorar la situación del reo. Sentencian dictada por la Primera Sala ${ }^{37}$ de la Corte Suprema de Justicia, de fecha 10 de febrero de 1954.

- Sentencia penal impugnada únicamente por el representante del Ministerio Público: dictamen del Ministerio Fiscal General favorable al encausado.

- Sentencia dictada por la Quinta Sala ${ }^{38}$ de la Corte Suprema de Justicia, con fecha 27 de marzo de 1984. Sentencia pronunciada por la Cuarta Sala ${ }^{39}$ de la Corte Suprema de Justicia, con fecha julio 14 de 1989, dentro del juicio penal que por muerte de Moisés Aldeán se sigue en contra de Jorge Cevallos.

- Corte Suprema de Justicia. Primera Sala de lo Penal ${ }^{40}$. Quito, 27 de junio del 2003.Las 10h00. Voto salvado del doctor Carlos Riofrío Corral.

- Resolución de Segunda Sala Penal especializada de la Corte Suprema de Justicia, Gaceta Judicial, serie XVII, número 14, página 4690.

33 Espinoza M., Diccionario de jurisprudencia..., tomo VI, segunda serie, 575-576.

34 Espinoza M., La más práctica enciclopedia jurídica..., 746. Igual criterio se aprecia en sentencias expedidas por la primera y tercera sala de la Corte Suprema de Justicia, respectivamente, el 21 de marzo de 1983 y el 7 de abril de 1976.

35 Juan Larrea Holguín, Repertorio de jurisprudencia (1976), tomo VI, sección penal, voz: Reformatio in pejus (Quito: Corporación de Estudios y Publicaciones, 1986), 473.

36 Larrea Holguín, Repertorio de jurisprudencia (1976)..., 472.

37 Fallo tomado de la obra de Espinoza M., La más práctica enciclopedia jurídica..., 747.

38 Fallo tomado de la obra de Espinoza M., La más práctica enciclopedia jurídica..., 747.

39 Segunda Sala de la Corte Suprema de Justicia, Prontuario de jurisprudencia, tomo I (Quito: Imprenta Marving, 1989). Fallo No. P. 88.003, fecha: marzo 7 de 1988. Juicio que por la muerte de Antonio Zamora se siguió en contra de Héctor Enríquez y otro.

40 Gaceta Judicial, serie XVII, No. 12, pp. 3858 a 3859, mayo-agosto, 2003. 


\section{FORMAS JURÍDICAS DE LIMITAR O FUNDAMENTAR EL PRINCIPIO DE LA REFORMATIO IN PEJUS}

\section{VII.1. Una propuesta de abolición de la probibitio reformatio in pejus}

Esta propuesta crítica ha sido expuesta brillantemente por el gran procesalista colombiano Hernando Davis Echandía, ${ }^{41}$ que, aunque dirigida para el derecho procesal civil y no al proceso penal, por su interés la exponemos. El maestro colombiano nos informa respecto de este principio que su fuente originaria era la doctrina que explicaba el proceso como una especie del "cuasi contrato de litis contestatio", eminentemente privado, de esta figura procesal y la necesidad de erradicarla desde perspectivas de política legislativa "del interés público”. La prohibitio reformatio in pejus, según el profesor colombiano, es “...un fósil jurídico totalmente fuera de lugar en el proceso moderno" (p. 284). Este principio, en relación con el Art. 357 del Código de Procedimiento Civil colombiano señala: “...La apelación se entiende interpuesta en lo desfavorable al apelante, y por lo tanto el superior no podrá enmendar la providencia en la parte que no fue objeto del recurso, salvo que en razón de la reforma fuere indispensable hacer modificaciones sobre puntos íntimamente relacionados con aquella...".

VII.2. Una cuestión procesal de fondo: ¿los recursos deben resolverse siempre en favor del reo, o deben resolverse en favor de todos los sujetos procesales?

Esta cuestión procesal parece tener dos filos cortantes de un mismo instrumento. a) La primera es que históricamente los recursos o remedios procesales fueron creados para que un superior revise una causa en orden a evitar un perjuicio al reo; es decir, en beneficio de quien recibe la coacción estatal. ${ }^{42}$ b) La otra posición indica que igual se causa perjuicio al procesado como a la víctima, al no reconocerles sus derechos, por lo que ambos tienen derecho ${ }^{43}$ a

41 Ver: Hernando Davis Echandía, Estudios de derecho procesal, tomo 1 (Bogotá: ABC, 2007), 282 y ss.

42 En esta posición dogmática: Julio Bernardo José Maier, Derecho procesal penal, segunda edición, tercera reimpresión, tomo 1 (Buenos Aires: Editorial del Puerto, 2004), 711 y ss. Otros detalles complementarios al respecto pueden verse en Maier, Derecho procesal penal, segunda edición, tercera reimpresión, tomo... 1145, 332, 384 y 431. De esta corriente puede verse a Alberto Bovino, Temas de derecho procesal guatemalteco (Guatemala, 1996), 262. Idem Daniel R. Pastor, La nueva imagen de la casación penal (evolución histórica y futuro de la dogmática de la impugnación en el derecho procesal penal), primera edición (Buenos Aires: AD-HOC, 2001), 130 y ss. Empero, el desarrollo de este principio, de una manera técnica aplicada desde el punto de vista de los efectos en la casación penal, siempre a favor del procesado, se presenta en el libro de Fernando de la Rúa, La casación penal (el recurso de casación penal en el nuevo Código Procesal de la Nación), con la colaboración de Fernando Díaz Cantón, segunda edición (Buenos Aires: Lexis Nexis, 2006), 272 a 276.

43 La otra posición dogmática, con fundamento desde el derecho constitucional es la de Germán Bidart Campos, "La doble instancia en el proceso penal (La Convención Americana Sobre derechos Humanos de San José de Costa Rica)", Revista Jurídica El Derecho, n. ${ }^{\circ}$ 7, 879; y la de Néstor P. Sagues, "La instancia judicial plural en la Constitución argentina y en el Pacto de San José de Costa Rica", La Ley (1988-E): 160. En el campo procesal penal argentino vemos seguir esta corriente a D’Albora, Código Procesal Penal de la Nación (Buenos Aires, 1996), 564. Tal vez, el autor argentino contemporáneo de más significación en esta corriente sea: José I. Cafferata Nores, Proceso penal y derechos humanos, segunda edición actualizada (Buenos Aires: CELS, Editorial del Puerto, 2008), 186 y ss. 
acudir ante el superior para la revisión de sus causas. El criterio que a este respecto lleguemos a mantener orientará la política criminal de si la prohibición de reformación peyorativa sea solo a favor del reo o también a favor de todos los sujetos de la relación procesal.

\section{VII.3. Las limitaciones al principio que estamos estudiando}

\section{- La adhesión al recurso}

Una de las formas de limitar este principio es la de admitir en materia penal la figura de la adhesión al recurso a las partes, de modo que ante cualquiera de las formas de impugnación que interponga el procesado, bastará con la adhesión a dicho recurso por parte del Ministerio Público en contra del procesado; o del acusador particular igualmente, para que el superior o ad quem obligado legalmente a atender a las otras partes procesales pueda libremente examinar también las pretensiones procesales adversas al reo.

Nuestra jurisprudencia se ha debatido en aceptar ${ }^{44}$ o no ${ }^{45}$ la adhesión al recurso, que es una figura del proceso civil, que en el COGEP ecuatoriano está expresamente aceptada para el recurso de apelación (Art. 263 COGEP), aunque no para el recurso de casación (Art.277 inciso final COGEP), mientras hay un vacío o silencio al respecto en la legislación procesal penal, en donde se discute si cabe utilizar esta figura procesal proveniente del proceso civil, de manera supletoria en materia procesal penal, nuestra mejor doctrina ${ }^{46}$ se pronunciaba a favor de esta figura procesal.

La doctrina anterior en el Ecuador no es unánime. Sin embargo, considero que, siendo posible la adhesión al recurso, no puede tenerse como perjudicial a la prohibición de reforma en perjuicio, pues en algunos casos es posible realizar en el tribunal de alzada algunos cambios al fallo venido en grado, que no necesariamente se deba de entender se realiza un perjuicio al procesado recurrente, sino que es una especie de correctivo del mismo sin que, en lo principal, se afecte la punición que subió por recurso.

\section{- La consulta al superior}

Otra forma de afectación es la figura de la consulta ${ }^{47}$ de las sentencias absolutorias y providencias liberatorias, que es una forma de recurso ex oficio, para que el superior fiscalice y

44 Jurisprudencia que sí cabe adhesión al recurso: Gaceta Judicial serie VIII, número 7, Gaceta Judicial serie VIII, número 9.

45 Jurisprudencia que no cabe adhesión: Gaceta Judicial serie VIII, número 9, página 859; Gaceta Judicial serie IX, número 15. Idem en Gonzalo Merino Pérez, Jurisprudencia civil y penal, tomo VIII, (Guayaquil: Escorpio), 179-180.

46 Jorge Zavala Baquerizo, El proceso penal ecuatoriano, tomo V, segunda edición (Guayaquil: Senefelder, 1975), 77. Modernamente, véase, Jorge Zavala Baquerizo, El proceso penal, tomo IV (Bogotá, 1990), 426-427 y ss. Como se ve, se pronuncia decididamente en favor de la adhesión al recurso de apelación.

47 Más en detalle ver Robert Guevara Elizalde, "Estudios sobre la ley de sustancias estupefacientes y psicotrópicas: el auto o sentencia judicial en consulta al superior. Su estado actual en el Ecuador", inédito (Guayaquil, 2010). Recientemente este ensayo fue publicado en Lex 14, n. $^{\circ} 18$ (2016).

Puede verse también en la página electrónica http://2.dx.doi.org//10.021-503//lex.u.14-18:1240 
revise o examine totalmente el proceso elevado a su conocimiento, en orden a que el juez superior o ad quem dicte libremente lo que a su criterio ilimitadamente ${ }^{48}$ corresponda, en derecho, decidir (revocar, reformar, confirmar sustituir, etc.) respecto de la providencia sometida a su consulta; parece obvio, que en muchos casos está libertad del juzgador parece coartada o vinculada por lo que decida el funcionario superior de la Fiscalía, aunque en la práctica así ha ocurrido en un gran caso de jueces timoratos; pero no necesariamente cuando se cuenta con jueces capaces, valientes y/o verdaderamente independientes.

\section{- La supresión indirecta de la reformatio in pejus}

La forma más usual de afectar el principio de la prohibición de reformar en perjuicio del procesado es la de abolirla indirectamente, o relativizándolo, al conceder el mismo beneficio a todas las partes procesales, incluidos los acusadores. Esto es que el beneficio de no afectar al reo en sus derechos adquiridos en el proceso por la sola interposición de recursos como único recurrente ahora se extiende a los demás sujetos procesales.

De modo que si el procesado interpone recurso sobre la pena impuesta o sobre alguna resolución judicial que le causa agravio, empero a la vez interponen recursos el acusador particular y el Ministerio Público por considerar que la pena impuesta es ilegítima por ser diminuta (por ejemplo, cuando se lo sanciona como encubridor cuando debió ser condenado como autor o cómplice; o cuando no se le impuso las penas accesorias que señala la norma punitiva; o cuando se le conceden atenuantes cuando existen varias agravantes, o existe prohibición legal expresa de conceder atenuantes por lo que no se debió modificar la pena; o cuando no existen las condiciones de modificación de la pena favorables al reo y sin embargo el juez las concede). O porque la resolución interlocutoria no es ajustada a derecho (por ejemplo, si se lo llama a juicio por encubridor, cuando debió ser llamado por autor o cómplice; o cuando se lo absuelve en vez de llamarlo a juicio; o cuando se sobresee definitivamente cuando se lo debe de sobreseer provisionalmente).

Sin embargo, debe de quedar claro que, si solo interpone recurso el acusador o el fiscal, y no lo hace el procesado, eso no lo vincula necesariamente al juez para la agravación en perjuicio del procesado.

Pues, esa impugnación que proviene exclusivamente o únicamente de la parte acusadora no le quita facultad al juzgador para dentro de la independencia y autonomía de su potestad

48 Ver Resolución de Consulta Dictada por la Tercera Sala de lo Penal de la Corte Suprema de Justicia, caso No. 88-2005, publicada en el Registro Oficial No. 88 de 21 de mayo del 2007, en donde se lee: "Es una institución que permite a un Tribunal superior examinar tanto el proceso como los fundamentos de hecho y de derecho en que ampara el juez a quo el auto resolutorio o la sentencia, según el caso. La consulta no tiene límites para el Tribunal de Alzada por lo que este puede revocar en su totalidad el fallo del inferior, lo que puede revocar en parte, o puede ratificar la resolución venida en consulta, vale decir que se trata de un examen ex officio que permite examinar la actuación del inferior...”. 
juzgatoria, si del contenido de las tablas procesales no haya fundamento para acoger el recurso de la parte acusadora y en consecuencia se amerite más bien, resolver de manera pro-reo o mejorando la situación del procesado.

\section{- Limitación parcial de la reformatio in pejus}

Finalmente, otra forma de limitar este principio es la de admitir este principio solo para los casos de sentencias sancionatorias o condenatorias; empero, no para meros autos interlocutorios, o para resoluciones incidentales importantes, como la concesión o negativa de dictar el auto de prisión preventiva; de concesión o denegación de la libertad personal; concesión o negación de caución excarcelaría; concesión o negación de las medidas sustitutivas o alternativas a las prisión preventiva o a las penas; etc. De modo que los casos de autos interlocutorios que cierran una estación procesal y deciden sobre llamar a juicio o las diversas de formas de sobreseimiento, antes en vigencia, actualmente solo hay un único sobreseimiento; así como a las diferentes formas de resoluciones incidentales importantes dentro del proceso penal no se aplica este principio, concebido solo para las sentencias condenatorias.

Nótese que este principio también puede ser conculcado cuando la suspensión condicional de la pena es revocada o reemplazada por una pena de efectiva privación de libertad, o si una pena de prisión es reemplazada por una pena de reclusión menor ordinaria, si la pena menor ordinaria es reemplazada por una pena mayor extraordinaria, o si la pena mayor extraordinaria es reemplazada por una penal especial, o si una pena de prisión de corta duración es remplazada por una pena más prolongada. Esta prohibición debe afectar también a las medidas de seguridad o a las penas accesorias, las modificatorias de que una pena de multa se cambie por una pena de prisión, aunque sea susceptible de suspensión condicional.

\section{- La declaratoria de nulidad}

Ejemplo es el caso de cualquiera decisión judicial que se impugna ante el superior, cuando cabe declaratoria de nulidad, por el ad quem por graves defectos de formalidad, de falta de ritualidad forense o de omisión de solemnidades sustanciales que hubieren influido en la decisión de la causa, siendo ineludible y obligatoria tal declaración de nulidad, en los casos que proceda, aun cuando las partes no hubieren interpuesto tal recurso, debe afectar al recurrente, dado que las causas de nulidad no son disponibles por las partes procesales. De modo que lo favorable o ganado por el procesado ante el inferior puede quedar declarado nulo por el superior. Y no puede dudarse de que tal decisión jurisdiccional produce el efecto de invalidar el proceso para todos los justiciables intervinientes hayan o no interpuesto recurso (distinto del de nulidad). Siendo la nulidad que mira al interés público, las partes procesales se someten a ella tácitamente.

Un fenómeno reciente se está dando en nuestra jurisprudencia sobre anulación de sentencias o de autos favorables, a procesados que no convengan política o socialmente a cierta línea de Gobierno. 


\section{- La apelación del auto de sobreseimiento solo por el fiscal}

La apelación del fiscal frente al sobreseimiento del procesado que dictan los jueces es una forma de atacar, por el Ministerio Público, la situación de inocencia, buscando empeorar la situación procesal del sobreseído. En regímenes autoritarios o de seguridad ciudadana es evidente la política criminal que auspiciaba ${ }^{49}$ se suprima el recurso de apelación del procesado llamado a juicio y, en cambio, se conceda la apelación del fiscal respecto del sobreseimiento.

\section{- Otras variables del perjuicio}

Las diferentes formas como puede aparecer el perjuicio contra el procesado, y ahora contra el recurrente, son muchas que no podemos desarrollar en un brevísimo estudio como el presente, pero, por ahora, únicamente las señalamos:

- Penas impuestas por el superior vulnerando el principio de legalidad penal.

- Penas impuestas por el tribunal penal o por el ad quem, vulnerando el principio de congruencia.

- Incrementando o imponiendo las penas accesorias y las medidas de seguridad a veces no solicitadas por la acusación.

- Incrementando montos y formas de pago sobre reparación civil. ${ }^{50}$

- Imponiendo penas mayores a las solicitadas por el acusador particular o por el fiscal.

- Alegándose estar firmada la condena o ser cosa juzgada.

- Reparando aparentemente las omisiones del inferior que permitieron una pena blanda, para corregir después agravando la decisión.

49 Ese cambio se logró en el Ecuador, por medio de la Ley reformatoria al Código penal y al Código de procedimiento penal, publicado en el Suplemento del Registro Oficial $N^{\circ} 160$ de lunes 29 de mayo del 2010, Art. 17 que reformó el Art. 343 del CPP, antes en vigencia. Lo asombroso del sometimiento de nuestra Corte Constitucional al poder central fue la Resolución del caso $\mathrm{N}^{\circ} 029-10$-IN resuelto el 4 de abril del 2013, que señaló que era constitucional la supresión de este recurso de apelación, Resolución que se publicó en el Suplemento del Registro Oficial Nº949 de miércoles 8 de mayo del 2013. Ahora en el COIP Art. $653 \mathrm{~N}^{\circ} 3$, se mantiene esa supresión.

50 Jurisprudencia de casación. Por ejemplo, en el juicio de tránsito por lesiones inferidas a José Frank Alvarado Cabrera contra Darío Javier Lascano Saavedra, dictada en Quito por la Sala Especializada de lo Penal, Militar, Penal Policial y de Tránsito, compuesta por los magistrados Merck Benavidez, Lucy Blacio, y Mariana Yumbay Yarico, con fecha 5 de marzo del 2012, a las 15H30, dicta sentencia de mérito de casación confirmando la penal y modificando la pena pecuniaria, que había elevado o agravado la tercera Sala Penal de la Corte provincial de Justicia de Guayaquil, rebajándola de treinta y nueve remuneraciones básicas a una multa de diez remuneraciones (fs. 429 y ss.), que es la que había originalmente fijado el A quo: Juzgado Quinto de Tránsito de Guayaquil, por vulnerar el principio de la prohibitio reformatio in pejus. 
- El beneficio de la extensión de los resultados del recurso.

- La prohibitio reformtio in pejus funciona también para cuestiones procesales. ${ }^{51}$

\section{LA REFORMATIO IN PEJUS EN EL DERECHO CONSTITUCIONAL ECUATORIANO}

A nivel de las Cartas Políticas del país, el principio recién apareció en la Constitución de 1998 (Art. 24, No. 13) que decía: "Al resolver la impugnación de una sanción, no se podrá empeorar la situación del recurrente".

Ante una demanda de inconstitucionalidad ${ }^{52}$ a este respecto, el Tribunal Constitucional del Ecuador extendió este principio en estudio, y cambiando el sentido original del mismo, resolvió:

Art. 328.: La demanda señala que se viola el derecho de defensa por que el numeral 13 del Art. 24 de la Constitución Política de la República, no pone limitación alguna al derecho para que en una apelación no se empeore la situación del recurrente, cuando el artículo impugnado limita esta garantía estableciendo que ello se refiere solo a cuando el imputado fuere el único recurrente.

La norma pretende que se llegue a la realización de la justicia SOBRE TODO PARA EL CASO DE QUE SE HUBIESE IMPUESTO UNA PENA IRRISORIA Y SI EXISTEN VARIOS APELANTES, DEBE SER POSIBLE QUE SE REVISE LA PENA Y DE SER EL CASO SE AGRAVE LA MISMA. ${ }^{53}$ (Las mayúsculas son mías.)

Y en la vigente Constitución del 2008 (Art. 77 No 14), se mantuvo esa doctrina, que relativiza este principio en estudio; pues, en el texto de la superley se lee: "Al resolver la impugnación de una sanción no se podrá empeorar la situación de la persona que recurre."

En los Arts. 58, 59, y 60 del Código Orgánico Integral Penal, en vigencia, establece las penas peculiares aplicables a las infracciones, que las menciona genéricamente entre las penas que se imponen en virtud de sentencias firme, de modo que estas sanciones específicas integran la pena en general; y es sobre aquellas que hay que examinar objetivamente para saber si estamos ante un perjuicio en el fallo de alzada respecto del fallo del $a$ quo.

51 En ese sentido, ver César San Martín Castro, Estudios de derecho procesal penal (Lima: Editora y Librería Jurídica Grijley, 2012), 486. Idem: Julio Bernardo José Maier. Derecho procesal penal (parte general, actos procesales)..., 313 y ss. Por lo demás, cuando el recurso versa sobre materia procesal, "si bien existen casos claros que permiten ponderar el beneficio o el perjuicio para el recurrente en comparación con la resolución que él recurre, en variadas ocasiones no permite una ponderación tan clara menos aun ex ante".

52 Ver Resolución del Tribunal Constitucional adoptada en las sesiones de 25 de abril, 21 de mayo, y 22 de mayo del 2001, caso Jorge Zavala Baquerizo contra Presidente Constitucional de la República, por la inconstitucionalidad del CPP de 2000-2001, caso No. 013.2000.TC.

53 La jurisprudencia nacional procesal penal moderna está adoptando este criterio. 


\section{CONSTITUCIÓN VERSUS NORMAS PROCESALES REFORMATORIAS}

Debemos ser enfáticos en el hecho de que ninguna de las Constituciones del Ecuador había recogido el principio de la prohibitio reformatio in pejus, sino solo hasta la Constitución de 1998, y que ahora con alguna variante, que relativiza el principio, la tiene la Constitución del 2008, como vimos anteriormente.

En general, siempre en épocas de supuesto o verdadero auge delictivo, siendo más redituable políticamente (populismo penal) el pregonar reformas a nuestro derecho penal, como incremento de penas y aparición de nuevos tipos penales, que la doctrina llama de "mano dura", se pretende siempre en ese denominado "derecho procesal penal del enemigo", suprimir algunas garantías procesales a través de un recorte de derechos (derecho procesal penal de enemigos), fruto de aquello y fundándose aparentemente de una corriente procesal penal chilena que propugna "la eficacia" y "la desformalización excesiva", se suprimieron derechos procesales que la práctica forenses y la jurisprudencia se habían históricamente consolidado de cierta manera, por lo que, para la "modernización" ${ }^{4}$ de garantías, fue menester incorporar cambios en la Constitución y en las leyes procesales "en vigencia".

Es obvio que las reformas a las leyes procesales que deben estar incorporadas al "bloque de constitucionalidad" 55 , para su constitucionalización y "legalización", carecerían de eficacia si son restrictivas de derechos, si atacan el principio de progresividad de los derechos constitucionales o el principio de la prohibición de regresividad de los derechos concedidos a los ciudadanos, normas que, en los actuales momentos están recogidos en los tratados de derechos Humanos ratificados por el Ecuador, atendiendo las características de la supremacía ${ }^{56}$ constitucional y en especial por lo previsto en garantías, en el Art. 84 de la Constitución del 2008

\section{LA SITUACIÓN DEL PRINCIPIO REFORMATORIO PEYORATIVO EN EL CPP DEL 2000-2001:}

El Art. 93 de las reformas legales al CPP y al CP publicadas en el Suplemento del Registro Oficial No. 555 de 24 de marzo del 2009, al reformar el Art. 328 del CPP, menoscabaron este derecho del acusado o procesado, al ampliar dicho beneficio a cualquiera de las partes procesales recurrentes.

54 Para más detalle sobre estos temas, ver Robert Guevara Elizalde, Politica criminal en el Ecuador, en el derecho penal de la postmodernidad, con prólogo de Carlos Parma (Guayaquil, 2015).

55 Ver el concepto de bloque de constitucionalidad en Robert Guevara Elizalde, Los derechos fundamentales en tiempos de neoconstitucionalismo, inédito (Guayaquil, 2014).

56 Título IX. Supremacía de la Constitución. Capítulo primero. Principios. Art. 424.- La Constitución es la norma suprema y prevalece sobre cualquier otra del ordenamiento jurídico. Las normas y los actos del poder público deberán mantener conformidad con las disposiciones constitucionales; en caso contrario carecerán de eficacia jurídica. La Constitución y los tratados internacionales de derechos humanos ratificados por el Estado que reconozcan derechos más favorables a los contenidos en la Constitución, prevalecerán sobre cualquier otra norma jurídica o acto del poder público. 
Incluso desde una perspectiva constitucional, la protección de no afectar al recurrente (no a favor del reo, sino en general) aparece recién con la Constitución de 1998 (Art. 24 No. 13), en que se lee: “Al resolver la impugnación de una sanción...”. Y en la Constitución del 2008 (Art. 77 No. 14), en que se lee:

"Al resolver la impugnación de una sanción...". Es decir, la norma constitucional limitó este principio solo para la sentencia condenatoria, al evitar mencionar en la norma a la sentencia absolutoria o a otras providencias o resoluciones que afecten derechos del recurrente. Aunque la norma constitucional la amplió a favor de otros sujetos procesales distintos al procesado.

La legislación ordinaria procesal penal amplió los alcances de la norma constitucional, y con ella mejoró el "halo" de esta protección al destinarla "al resolverse cualquier recurso" (Art. 328 CPP reformado). También amplió pues este principio en cuanto a sus benefactores que antes era solo el reo o acusado, y que ahora beneficia a todas las partes procesales, con lo que al extender sus beneficios a todas las partes procesales (no solo en exclusiva del reo) implícitamente, indirectamente se restringió legalmente a este — al procesado — su derecho, que era tradición jurisprudencial mayoritaria sea favorable al encausado.

Que con las reformas (Suplemento al RO 555) al CPP del 24 de marzo del 2009, se amplía este beneficio para las otras partes procesales, sin que eso quiera decir que el juez quede vinculado u obligado a aceptar todas las peticiones contenidas en el recurso de los impugnantes distintos al condenado. Ante estas nuevas condiciones procesales, la única obligación del juez penal ad quem es la de no empeorar tal situación del recurrente, cualquiera sea esta; pero no está obligado, por ello, a empeorar la situación del procesado, solo por el hecho de "... no ser el único recurrente", ${ }^{57}$ si este no lo merece. ${ }^{58}$

Obviamente que si el recurrente es el accionante, cualquiera que este fuere (acusador particular, o el fiscal,), y si además tiene el derecho y la justicia de su parte, naturalmente el juez debería en derecho aceptar tal remedio solicitado por la acusación contingente o por la acusación necesaria, aunque perjudique al reo.

57 Ver sentencia de casación No. 526-2009, de fecha 25 de junio del 2009, Segunda Sala Penal de la Corte Nacional de Justicia del Ecuador, juicio por atentado al pudor, respecto de sentencia condenatoria del Tribunal Penal de Morona Santiago contra el acusado Luis Chiriap Ankuash, fallo que declara improcedente el recurso de casación interpuesto por el condenado. Pero, en donde se argumenta: “...sin que pueda considerarse la institución de la Reformatio in Pejus, a su favor, por no tener la calidad de único recurrente...”. Tomado del libro Colección de jurisprudencia 2009 - II (Quito: Ediciones Legales, Corporación MYL, 2011), 317.

58 En este sentido también Zavala Baquerizo, Tratado de derecho procesal penal, tomo X..., 67.

Idem ver Vicente Robalino V., 200 Proyectos de actuaciones policiales, fiscales, judiciales, profesionales, según el Nuevo Código de Procedimiento Penal (Ambato, 2001), 187. En otro sentido, similar, pero con argumento inverso, ver Maximiliano Blum Manzo, Procedimiento penal (apuntes jurídicos), segunda edición, (Guayaquil, 2010), 425, donde dice: "En consecuencia, apele el fiscal o el acusador, o ambos, pero también recurre el procesado o acusado, por lo dispuesto en el CPP no puede empeorarse la situación jurídica del recurrente, cualquiera sea la providencia impugnada”. 


\section{LA SITUACIÓN ACTUAL DE LA NUEVA ABOLICIÓN DEL PRINCIPIO DE LA PROHIBICIÓN REFORMATORIA PEYORATIVA EN EL COIP}

El último de los proyectos del Código Orgánico Integral Penal, en la parte procesal, había señalado a este respecto que "El tribunal de garantías penales, al conocer una impugnación de una sanción, no empeorará la situación jurídica de la persona sentenciada."

Como novedad del COIP, se consigna que el principio de la reformatio in Pejus, ${ }^{59}$ contenido en el Art. 5 No. 7 y Art. 652 No. 7 del COIP, consagrado además por nuestra jurisprudencia, ${ }^{60}$ en la legislación procesal anterior 2000-2001 reformada en virtud de las reformas de marzo del 2009, abandonó la estricta protección al procesado; y se amplió en su protección, pues, cualquiera que fuere el apelante, aunque sea el fiscal o el acusador particular, y en "cualquier recurso, no se podrá empeorar la situación jurídica del recurrente" (abandono la palabra procesado).

El COIP en el Art. 5 No. 7 dice: "Al resolver la impugnación de una sanción no se podrá empeorar la situación de la persona procesada cuando esta es la única recurrente".

Más adelante en el Art. 652 No. 7 del COIP en vigencia dice: "El tribunal de alzada, al conocer la impugnación de una sanción, no empeorará la situación jurídica de la persona sentenciada cuando sea la única recurrente.

Es decir, el COIP, al agregar la frase "cuando sea la única recurrente", que el anterior proyecto del COIP no la tenía, en esta materia, sigue la misma línea del CPP anteriormente vigente, reformado, apartándose de la línea histórica original de protección exclusiva del reo, por una línea de posible agravación si concurren en alzada con el reo los otros sujetos procesales.

Conclusión: Se confirma una vez más en el derecho procesal penal del Ecuador, el abandono a galope de varias figuras de protección o garantía del procesado. Estamos ante una nueva abolición del principio de la prohibitio in reformatio in pejus; empero, intercambiadas ahora por una legislación que afirma eficazmente la condena más grave a los ciudadanos sometidos a juicio.

59 Uno de los primeros ensayos en el país, al respecto de esta figura en la doctrina nacional, puede verse en Alfonso Zambrano Pasquel, "La abolición de la reformatio in pejus", La Ley, n. ${ }^{\circ} 6$ (julio de 2017).

Un estudio más actualizado y más extenso sobre esta institución es el de Robert Guevara Elizalde, "La reformatio in pejus en el Ecuador", inédito (Guayaquil, 2013), expuesto en varias conferencias dentro y fuera del país.

60 Jurisprudencia: ver Gaceta Judicial serie XIII, número 10, página 2201; Gaceta Judicial serie XVII número 13, página 4226; Gaceta Judicial serie XVII, número 12, página 3853. 


\section{REFERENCIAS}

- Abarca Galeas, Luis Humberto. La defensa penal oral. Tomo IX. Primera edición. Quito: Editorial Jurídica del Ecuador, 2008.

- Bernal Cuéllar, Jaime y Eduardo Montealegre Lynnet. El proceso penal. Tercera edición. Bogotá: Universidad Externado de Colombia, 1995.

- Bidart Campos, Germán. "La doble instancia en el proceso penal (la Convención Americana sobre Derechos Humanos de San José de Costa Rica)". Revista Jurídica El Derecho, n. ${ }^{\circ} 7$.

- Blum Manzo, Maximiliano. Procedimiento penal (apuntes jurídicos). Segunda edición. Guayaquil, 2010.

- Borrero Vega, Antonio. Estudio del código de procedimiento penal. Cuenca: Talleres Gráficos de la Universidad de Cuenca, 1951.

- Bovino, Alberto. Temas de derecho procesal guatemalteco. Guatemala, 1996.

- Cabezas Borja, Reynaldo. Proyectos de Código Penal y de Procedimientos Penales para la república del Ecuador. Quito: Talleres Gráficos Nacionales, 1948.

- Cafferata Nores, José I. Proceso penal y derechos humanos. Segunda edición actualizada. Buenos Aires: CELS, Editorial del Puerto, 2008.

- Claria Olmedo, Jorge E. Derecho procesal penal. Con la colaboración de José Cafferata Nores, Cristina José de Cafferata y Jorge Montero. Tomo II. Córdova: Marcos Lerner, 1984.

- Colección de jurisprudencia 2009- II. Quito: Ediciones Legales, Corporación MYL, 2011).

- Cueva Carrión, Luis. El debido proceso. Segunda edición. Quito: Ediciones Cueva Carrión, 2006.

- D’Albora, Francisco. Código Procesal Penal de la Nación. Buenos Aires, 1996.

- Davis Echandía, Hernando. Estudios de derecho procesal. Tomo 1. Bogotá: ABC, 2007.

- De la Rúa, Fernando. La casación penal (el recurso de casación penal en el nuevo Código Procesal de la Nación). Con la colaboración de Fernando Díaz Cantón. Segunda edición. Buenos Aires: Lexis Nexis, 2006.

- Díaz de León, Marco Antonio. Diccionario de derecho procesal y de términos usuales en el proceso penal. México D. F.: Porrúa, 1986.

- Espinoza M., Galo. Diccionario de jurisprudencia de la Corte Suprema de Justicia. Tomo VI. Quito: Imprenta del Colegio Don Bosco, 1984. 
Diccionario de jurisprudencia de la Corte Suprema de Justicia. Tomo IV. Segunda serie. Quito: Imprenta del Colegio Don Bosco, 1984.

- Espinoza M., Galo. La más práctica enciclopedia jurídica: compendio de setenta años de jurisprudencia de la Corte Suprema de Justicia. Tomo IV. Quito: Imprenta Don Bosco, 1999.

- Espitia Garzón, Fabio. Instituciones de derecho procesal penal. Séptima edición. Bogotá: Legis, 2010.

- Fermín Cevallos, Pedro. Instituciones de derecho práctico ecuatoriano. Presentación del Dr. Fausto Sánchez H. Reimpresión de mayo de 1994. Quito: Consejo General de Instrucción Pública, 1867.

- García Falconi, José. Setenta años de jurisprudencia de la Corte Suprema. 78 años de jurisprudencia penal ecuatoriana. Primera edición. Quito: Producciones Gráficas, 1981.

Código de Procedimiento Penal con jurisprudencia. Quito: 1984.

- Gernaert Willmar, Lucio R. Manual de los recursos. Prólogo de J. E. Claria Olmedo. Buenos Aires: Abeledo Perrot, 1985.

- González García, Guillermo. Manual de procedimiento penal. Quito: Editorial Universitaria, 1967.

- Guerrero Vivanco, Walter. El proceso penal. Tomo IV. Cuarta edición. Quito: Pudeleco Editores S. A., 2004.

- Guevara Elizalde, Robert. "La prohibición de reformatio in pejus en el Ecuador". Inédito. Guayaquil, 2013.

"La reformatio in pejus en el Ecuador". Inédito.

Politica criminal en el Ecuador, en el derecho penal de la postmodernidad. Con prólogo de Carlos Parma. Guayaquil, 2015.

"Estudios sobre la ley de sustancias estupefacientes y psicotrópicas: el auto o sentencia judicial en consulta al superior. Su estado actual en el Ecuador". Lex 14, n. ${ }^{\circ} 18$ (2016): 131-180.

"Estudios sobre la ley de sustancias estupefacientes y psicotrópicas: el auto o sentencia judicial en consulta al superior. Su estado actual en el Ecuador". Inédito. Guayaquil, 2010. 
Los derechos fundamentales en tiempos de neoconstitucionalismo. Inédito. Guayaquil, 2014.

- Instituto de Ciencias Penales de la Facultad de Jurisprudencia de la Universidad de Cuenca. Anteproyecto de Código de Procedimiento Penal del Ecuador. Cuenca: Talleres Gráficos de la Universidad de Cuenca, 1963.

- Jauchen, Eduardo M. Derechos del imputado. Primera edición. Buenos Aires: Rubinzal Culzoni, 2007.

- Larrea Holguín, Juan. Repertorio de jurisprudencia (1976). Tomo VI. Sección penal. Voz: Reformatio in Pejus. Quito: Corporación de Estudios y Publicaciones, 1986.

- Laverde Noboa, Héctor Jaime y Juan Carlos Arias Duque. "Audiencias de sustentación oral de recursos". En El proceso penal acusatorio en Colombia. Las audiencias en el juicio oral. Primera reimpresión de la primera edición. Tomo II. Bogotá: Ediciones Jurídicas Andrés Morales, Bogotá, 2007.

- Levene, Ricardo. Manual de derecho procesal penal. Tomo II. Buenos Aires: Depalma, 1997.

- Llore Mosquera, Víctor. "Programa analítico para la enseñanza del derecho procesal penal". Anales de la Universidad de Cuenca XII, n. ${ }^{\circ} 3-4$ (julio-diciembre de 1956): 159- 263. Compendio de derecho procesal penal ecuatoriano. Tercera edición. Cuenca: Fondo de Cultura Ecuatoriano, Offset Atlántida, 1979.

- Maier, Julio Bernardo José. Derecho procesal penal. Segunda edición, tercera reimpresión. Tomo 1. Buenos Aires: Editorial del Puerto, 2004.

- Maier, Julio Bernardo José. Derecho procesal penal (parte general, actos procesales). Tomo III. Primera edición. Buenos Aires: Editorial del Puerto, 2011.

- Merino Pérez, Gonzalo, Jurisprudencia civil y penal. Tomo VIII. Guayaquil: Escorpio.

- Neyra Flores, José Antonio. Manual del nuevo proceso penal y de litigación oral. Lima: Idemsa, 2010.

- Pastor, Daniel R. La nueva imagen de la casación penal (evolución histórica y futuro de la dogmática de la impugnación en el derecho procesal penal). Primera edición. Buenos Aires: AD-HOC, 2001.

- Peña Cabrera Freyre, Alonso Raúl. Manual de derecho procesal penal (teoría, práctica y jurisprudencia). Con la colaboración de Raúl Gonzalo Peña Freyre. Segunda edición. Lima: Rodhas, 2008. 
- Quiceno Álvarez, Fernando, ed. Jurisprudencia penal. Repertorio jurisprudencial seleccionado. Primer semestre 2002. Primera edición. Bogotá: Editora Jurídica de Colombia Ltda., 2002.

- Rengel, Jorge Hugo. "Proyecto de Código de Procedimiento Penal". En Memorias de las VIII Jornadas Iberoamericanas de Derecho Procesal, tomo II, editado por la Corte Suprema de Justicia, 167-290. Quito: Editorial Ecuador, 1983.

- Robalino V., Vicente. 200 Proyectos de actuaciones policiales, fiscales, judiciales, profesionales, según el Nuevo Código de Procedimiento Penal. Ambato, 2001.

- Sagues, Néstor P. "La instancia judicial plural en la Constitución argentina y en el Pacto de San José de Costa Rica”. La Ley (1988-E): 156-171.

- Sánchez Velarde, Pablo. El nuevo proceso penal. Primera edición. Lima: Idemsa, 2009.

- San Martín Castro, César. Derecho procesal penal. Segunda edición actualizada y aumentada. Tomo II. Lima: Grijley, 2003.

2012.

Estudios de derecho procesal penal. Lima: Editora y Librería Jurídica Grijley,

- Segunda Sala de la Corte Suprema de Justicia. Prontuario de jurisprudencia. Tomo I. Quito: Imprenta Marving, 1989.

- Torres Chávez, Efraín. Breves comentarios al Código de Procedimiento Penal (con práctica penal). Volumen 2. Quito: Corporación de Estudios y Publicaciones, 2001.

- Vaca Andrade, Ricardo. Manual de derecho procesal penal. Volumen 1. Quito: Corporación de Estudios y Publicaciones, 2001.

- Vázquez Rossi, Jorge. Derecho procesal penal. Tomo II. Buenos Aires: Rubinzal Culzoni, 2004.

- Zambrano Pasquel, Alfonso. "La prohibición de la reformatio in pejus". La Ley, n. ${ }^{\circ} 6$ (julio de 1977): 23-29.

"La abolición de la prohibición de la reformatio in pejus". En Opúsculos penales. Guayaquil: Ediciones Jurídicas La Ley, 1977.

- Zavala Baquerizo, Jorge. El proceso penal ecuatoriano. Tomo V. Segunda edición. Guayaquil: Imprenta A. G. Senefelder, 1975.

El proceso penal. Tomo IV. Bogotá, 1990. 
- Zavala Baquerizo, Jorge. Exposición de motivos sobre las reformas al Código de Procedimiento Penal. Guayaquil: Colegio de Abogados del Guayas, 1984.

“Comentarios al Código de Procedimiento Penal", en Memorias del seminario de 30 de agosto al 2 de septiembre de 1983. Loja: Colegio de Abogados de Loja, 1985.

Tratado de derecho procesal penal. Tomo IX, X. Guayaquil: Edino, 2007. 